\title{
Proces podomačevanja in vprašanje pisanja novejših prevzetih besed
}

\author{
Aleksandra Bizjak Končar - Helena Dobrovoljc
}

\begin{abstract}
Prispevek obravnava vprašanje pisanja novejših v slovenščino prevzetih besed. Da bi pokazali, da je prevzemanje besed jezikovna sprememba, ki poteka postopoma, tako da $\mathrm{v}$ jeziku soobstajajo različne oblike, smo za raziskavo izbrali področje hrane in pijače. Analiza izbranega besedja, prevzetega v različnih časovnih obdobjih iz različnih jezikov, je pokazala, da je intenzivnost podomačevanja odvisna od prepleta jezikovnih, družbenih in psiholoških dejavnikov. V sklepnem delu pa opozorimo, da je spoznanja o podomačevanju kot procesu treba upoštevati pri slovarskem prikazu prevzetih besed.
\end{abstract}

Ključne besede: slovenščina, slovenski pravopis, prevzete besede

The nativization process and how recently borrowed words are written

This article examines how words recently borrowed into Slovenian are written. The semantic fields of food and drink were selected to demonstrate that lexical borrowing is a linguistic change that takes place gradually such that various forms coexist in a language. The analysis of selected words borrowed from various languages during various time periods shows that the degree of nativization depends on intersecting linguistic, social, and psychological factors. The conclusion emphasizes that findings on nativization as a process must be taken into account in the lexicographic presentation of borrowed words.

Key words: Slovenian, Slovenian written norm, borrowed words

\section{Uvod}

Prispevek obravnava vprašanje pisanja novejših prevzetih besed, ki prihajajo $\mathrm{v}$ slovenščino iz germanskih in romanskih jezikov. $Z$ leksikalnim prevzemanjem se je pri nas ukvarjala vrsta domačih avtorjev, vendar je bil namen teh prispevkov usmerjen v reševanje terminoloških zagat (Toporišič 1972; Snoj 2005), obravnavo prevzetih besed $\mathrm{z}$ vidika zapisa $\mathrm{v}$ jezikovnih priročnikih (Toporišič 1971; Pogačnik 2003) in opis posameznih prevzetih besed z razvojnega vidika (Bajec 1955/56). Pričujoči prispevek ima skromnejši cilj, saj želiva z opisom avtentičnega gradiva iz različnih virov prikazati, da proces prilagajanja tujega besedja zakonitostim slovenskega jezika ni vedno predvidljiv in je zato izziv za avtorje različnih jezikovnih priročnikov, ki se pri soočanju z raznolikostjo zapisanih oblik ne morajo vedno opreti na pravopisna priporočila. Vprašanje prevzemanja tujih besed v slovenščino je na načelni ravni namreč obravnavano v pravopisnih priročnikih. Že SP 1962 
določa, da v slovenščini besede, prevzete iz tujega jezika, pišemo »na dva načina, v tuji obliki ali po domači izgovarjavi« (§ 69). Merilo za ločevanje med podomačenim in nepodomačenim zapisom pa je področje rabe besede: prevzete besede, ki so »omejene le na ozek krog strokovnjakov ali družbe«, ohranjajo tujo obliko zapisa, prevzete besede, ki pa so »V splošni rabi«, pišemo »po domači izgovarjavi« (§ 70, 71). V pravopisnih pravilih iz leta 2001 merilo za ločevanje med podomačenim in nepodomačenim zapisom ni več razkrito, saj uporabnik v poglavju Prevzete besede in besedne zveze izve, da pisno domačimo »[v]ečino prevzetih občnih besed«. Tiste, ki naj bi ohranile izvirno pisavo, so razvrščene $\mathrm{v}$ štiri kategorije, a tudi zanje $\mathrm{v}$ pravopisu piše, da »S časom navadno prevzamejo slovensko pisavo po slovenskem izgovoru« (§ 168: kurikulum, džul, folksvagen itd.). Z uporabo besed s časom in navadno pravopis zakrito sporoča, da je slovenjenje prevzetih besed nepredvidljiv jezikovni proces, pri čemer ne moremo napovedati, katere podomačene oblike se bodo uveljavile prej ali katere od tujih oblik se ne bodo nikoli podomačile. Posamezne besede (npr. jogging, jeans), ki bi jih po jezikovnih pravilih podomačili na enak način (džoging, džins), se v sodobnih besedilih namreč zapisujejo različno (jogging, džins). Zdi se, da gre pri prevzemanju za proces spreminjanja jezika, ki ne poteka samo v odvisnosti od notranjih jezikovnih zakonitostih, ampak so zanje pomembni tudi vplivi družbenih in psiholoških dejavnikov. Že Labov (1972, po Aitchison 1991: 37-38) je ugotovil, da pogosto prav raznolikost in nejasnost nakazujeta, da se v jeziku dogajajo spremembe. Da bi pokazali, da je prevzemanje besed jezikovna sprememba, ki poteka postopoma, korak za korakom, tako da $\mathrm{v}$ jeziku soobstajajo različne oblike, ki med seboj tekmujejo, bomo za raziskavo izbrali področje, ki nam bo omogočalo najširši pregled gradiva.

\section{Opis tematskega področja in gradiva}

2.1 Pričujoča raziskava o leksikalnem prevzemanju v slovenščini temelji na analizi gradiva, ki obsega široko področje in ga je treba zaradi namena te raziskave omejiti. Pri izbiri tematskega področja smo se naslonili na spoznanja sodobnih sociolingvistov, ki so se s teorijo prevzemanja ukvarjali v okviru proučevanj, povezanih s stopnjo in intenzivnostjo stika dveh kultur in (posredno) jezikov (Thomason 2001; Thomason - Kaufman 1988), in se odločili, da za raziskovanje prevzemanja izberemo tematsko področje, ki omogoča zasledovanje vplivov tako jezikovnih kot družbenih dejavnikov in ustreza naslednjim merilom:

(1) področje je univerzalno za vse skupine jezikovnih uporabnikov,

(2) izrazje $\mathrm{s}$ tega področja je tako domače kot prevzeto, slednje pa se nahaja $\mathrm{V}$ različnih stopnjah podomačitve in ga večinoma ne uvrščamo v fond t. i. osnovne leksike,

(3) na področje vplivajo različna kulturna okolja oziroma na izrazje s tega področja vplivajo različni jeziki,

(4) leksiko je mogoče spremljati v daljšem časovnem intervalu, kar nam omogoča primerjanje procesa prevzemanja danes in $\mathrm{v}$ preteklosti tako $\mathrm{z}$ vidika intenzivnosti kot z vidika družbenih, tj. nejezikovnih vplivov. 
Upoštevajoč zgoraj našteta merila, smo se v raziskavi omejili na področje prehrane, ki je ena od temeljnih kulturnih dobrin in sodi med najbolj univerzalna področja človekovega bivanja. Prav univerzalnost ter vsakodnevna in življenjska pomembnost hrane nam ponujata možnost, da spremljamo in primerjamo pojavljanje in rabo prevzete leksike v različnih funkcijskih zvrsteh jezika in v daljšem časovnem intervalu.

2.2 Izrazje s področja prehrane se je v različnih obdobjih slovenščine razvijalo pod vplivom različnih kulturnih okolij oziroma jezikov. Zaradi družbeno-zgodovinskih okoliščin, v katerih je bila nemščina prevladujoči jezik pišočih Slovencev, je bil vse do zatona habsburške monarhije za hrano najintenzivnejši vpliv nemškega izrazja. Zato nas ne preseneča, da že v Vodnikovih Kuharskih Bukvah (1799), prvi slovenski kuharski knjigi, prevladujejo nemške izposojenke (npr. župa, kofe, jesih). Prevladovanje nemščine je opazno tudi v prvi slovenski izvirni kuharici avtorice Marije Magdalene Knafelj - Pleiweis iz leta 1868. ${ }^{1}$ Šele v drugi polovici 19. stoletja, ko je bilo treba poiskati oporo in alternativo germanski grožnji v slovanskem svetu, so nemške izposojenke »zamenjali s knjižnimi besedami, vzetimi iz drugih slovanskih jezikov« (Bajec 1955/56: 235), kar se odraža tudi v Pleteršnikovem Slovensko-nemškem slovarju (1894-1895). Tako za besede kofe, prevzete prek nemščine, ${ }^{2}$ Pleteršnik usmerja h kavi, prevzeti prek hrvaščine (kofe pogl. kava). Kako trdno so se nemške izposojenke zasidrale v rabi, pa dokazuje dejstvo, da tudi v obdobju, ko se je družbena vloga slovenščine okrepila in je ta postala uradni jezik, ter med obema vojnama v kuharicah ob slovenskih izrazih nastopajo pogosto tudi nemški. Na primer, v Spretni kuharici iz leta 1923, »sestavljeni po raznih virih«, najdemo pojasnila iz nemškega jezika (mornarski zrezki (Schnitzel), str. 46), pa tudi neknjižne izposojenke iz nemščine (gres, str. 15, slaninski (̌̌pehovi) štruklji, str. 23) in podobno.

V letih 1920-1940, ko slovenščino in južnoslovanske jezike poveže skupna državna tvorba, v slovenskih kuharicah najdemo že izraze iz hrvaškega, bosanskega in srbskega jezika, ki označujejo balkanske jedi (čufti, čevapčiči, džuveč, ražnjiči, ajvar). ${ }^{3}$ Ta težnja se nadaljuje tudi v obdobju po letu 1945, ko dobi jezikovni idiom, imenovan srbohrvaščina, v SFR Jugoslaviji položaj prestižnega večinskega jezika.

Vpliv romanskih jezikov, zlasti italijanščine, je bil v zahodni slovenski kuhinji opazen že od 15. stoletja. Bogataj (2008) navaja, da so mineštro kuhali Slovenci v Vipavski dolini že v Trubarjevem času. Sredi osemdesetih let 20. stoletja pa so se v slovenskih kuharicah množično pojavili izrazi iz italijanščine (na primer pica,

1 Pregledana je bila peta izdaja iz leta 1902. Avtoričin priimek je v nekaterih virih zapisan tudi kot Bleiweis.

2 O izvoru izraza kofe podrobneje pri kava (Bezlaj 1982: 24).

3 Knjiga R. Puclja 110 novih kuharskih receptov, izdana v Celju leta 1938, tako prinaša recepte za bosenske čufte (str. 11), jagnjetino in đuveć na »srbski način« (str. 11-12), srbski ajvar (str. 18) itd. 
lazanja, kaneloni, karpačo, tortelini) ter iz evropske ali latinskoameriške španščine (tortilja, fajita, gvakamole, kvinoja).

V nasprotju z nemščino predstavlja francoščina še danes prevladujoči jezik na področju kulinarike tako v svetu kot pri nas. Prva slovenska kuharica, v kateri je opazna naslonitev na francosko izrazje, je knjiga Iz francoske meščanske kuhinjeNad 1000 kuharskih receptov in pripombe o serviranju M. Moravec iz leta 1927. Da je danes francoščina uporabljena kot jezik glavnih (nosilnih) terminov, potrjuje veliko število francoskih citatnih izrazov ne le za jedi (soupe à l'oignon), temveč tudi za načine priprave hrane, način in vrsto strežbe (nouvelle couisine, à la carte), o čemer se lahko prepričamo tudi v aktualni slovenski Kuharski enciklopediji (Novak - Lenarčič 2009). Tudi ogled številnih jedilnih listov v središču Ljubljane nas prepriča, da so še vedno v rabi živa klasična francoska imena tako za glavne jedi (filet de saumon) kot za posamezne sestavine jedi, na primer kose mesa (chateaubriand, filets mignons), skorajda brezizjemo pa tudi za ocvrt krompirček (pommes frites), narastek (soufflée), peno (mousse), frape (frappé). ${ }^{5}$

Zaradi svoje posredniške vloge zavzema posebno mesto med tujimi jeziki angleščina. Angleško izrazje opazimo najprej v kuharicah iz dvajsetih in tridesetih let prejšnjega stoletja (biftek, sendvič) ${ }^{6}$ sicer pa je tesnejšo navezavo na anglosaško izrazje zaslediti zlasti od šestdesetih let dalje, ko je v slovenskih kuharicah ob francoskem tudi vedno več angleškega izrazja, ki se nanaša večinoma na jedi, ki sledijo trendu hitre prehrane (fast food, čips, hamburger), pijač (koktajl, gin fizz, bloody Mary) ter peciva (mafini, banana split). Prek angleščine, ki se uveljavlja kot globalni jezik, smo pridobili tudi izrazje iz kitajščine (čopsui, tofu), japonščine (suši, sake), arabskih jezikov (kuskus, falafel, humus, tahini) in drugih.

2.3 V nasprotju s preteklostjo, ko so bile možnosti za medkulturne vplive večinoma omejene na fizični stik, danes ob hitrem soočanju z novo, neznano predmetnostjo in zaradi hitro se spreminjajočih družbenih razmer, globalizacijskih procesov in iskanja alternativnih možnosti zdrave prehrane prevzeto izrazje za hrano prodira v slovenščino hitreje in po različnih poteh. Da gre tu za prevzemanje »imen za predmete in pojme«, ki smo jih prevzeli »iz tujih kultur«, torej za »potrebne izposojenke«, opozarja že Bajec v svoji razpravi o izposojenkah v slovenskem besedišču (1955/56: 235-237). Bajec namreč kategorizira t. i. kulturno izrazje in ga definira kot fond besed, ki naj bi bil pogosto »last« vseh kulturnih jezikov in ki jih vsak od njih prilagaja na sebi svojstven način (1955/56: 235). V sodobnih socioloških raziskavah se to izrazje uvršča $\mathrm{v}$ neosnovno leksiko in je povezano $\mathrm{z}$ zapolnjevanjem izrazne praznine (za razlikovanje med osnovnim in neosnovnim izrazjem gl. Thomason 2001: 70-71). Tuje lekseme nato na izrazni ravni prilagodimo našemu

${ }^{4}$ Npr. goveja juha (pot-au-feu) (Moravec 1927: 3), ocvrte krušne rezine (croûtons) (Moravec 1927: 66).

$5 \mathrm{Z}$ jedilnega lista $\mathrm{v}$ lokalu Le petit caffé na Trgu francoske revolucije v Ljubljani, maj 2010.

6 Irisch Stew (Spretna kuharica 1923: 48), obloženi kruhki ali sendviči (Sandwichs) (Moravec 1927: 65), zrezki od pljučne pečenke ali biftek, Bifteck, beefsteak (Moravec 1927: 135), iris stew (Kuharski recepti 1938: 45). 
jeziku. Ker gre pri prilagajanju za jezikovne spremembe, na katere vplivajo tudi družbeni in psihični dejavniki, se je za odločitve zapisu v priročnikih treba nasloniti na analizo gradiva.

2.4 Pojavljanje izbranega nabora izrazja s področja prehrane je bilo zato pregledano v obeh prosto dostopnih besedilnih korpusih, Nova beseda (bos.zrc-sazu.si) in FidaPLUS (www.fidaplus.net), ki večinoma ne vključujeta tematsko specializiranih besedil s tega področja, temveč predstavljata bodisi nabor poljudno zbranih leposlovno-časniških lektoriranih besedil, nastalih od 19. stoletja pa vse do leta 2008 (Nova beseda), bodisi zvrstno bolj uravnoteženih besedil iz omejenega obdobja, $\mathrm{tj}$. 1990-2006 (FidaPLUS). Zato je bilo treba aktualne podatke o zapisu in rabi besedja dopolniti s poizvedbami po spletnih straneh, in sicer z vidika najširših pojavitev (spletni dnevniki, priložnostna besedila, spletišča posameznih podjetij in spletnih forumov) kot tudi z vidika pojavitev na portalih, specializiranih za kulinarična področja (spletna portala Kulinarična Slovenija - www.kulinarika.net - in Gurman, društvo dobrih okusov - www.gurman.eu; besedila na slednja prispevajo zlasti tisti jezikovni uporabniki, ki se z vprašanji zapisa teh leksemov tudi najpogosteje srečujejo in se z njimi ukvarjajo). Med aktualnimi neelektronskimi viri je bila preverjena raba v tedenski prilogi časnika Delo z naslovom Odprta kuhinja, v kateri je zapis posamezne besede odvisen tudi od tega, kako ga gost revije, t. i. gostujoči kuhar, ki tudi predlaga tedenski jedilnik, zapiše sam.

Izrazna podoba nabora leksemov je bila preverjena tudi v obeh aktualnih normativnih slovarjih, tj. v SSKJ in SP 2001.

Da bi bila raziskava uravnotežena tudi terminološko, je bilo izbranih več avtorskih kuharskih knjig iz različnih obdobij druge polovice 20. in začetka 21. stoletja, ki smo jih razvrstili glede na to, ali so napisana izvirno v slovenščini ${ }^{7}$ ali pa so prevedena. ${ }^{8}$ Zapis in raba izbranih besed v besedilih sta bila za posamezne zglede preverjena tudi v aktualni Kuharski enciklopediji (Novak - Lenarčič 2009).

\section{Analiza prilagajanja prevzetega besedja slovenščini}

Preverjanje, kako uporabniki prevzete besede podomačujejo danes, bomo začeli z obravnavo tistih prevzetih besed za hrano in pijačo, ki so bile zapisane že v SSKJ (in SP 2001), a zanje še 20 let kasneje gradivo izpričuje neustaljenost zapisa.

7 Med izvirnimi slovenskimi kuharicami smo izbrali tele: Andreja Grum (ur.), Velika sodobna kuharica (1956); Ivan Ivačič, Kuharska knjiga (1965); Andreja Grum - Pepika Levstek, Kuharstvo (1983); Marija Ilc, Kuharica sestre Vendeline - Slovenska meščanska kuhinja (1994); Luka Novak - Valentina Novak Smej, Ljubezen skozi želodec (2009).

8 Izrazje je bilo preverjeno v tehle prevedenih kuharskih monografijah: Roland Gööck, Nova velika kuharska knjiga (prev. iz nem. 1968); Roland Gööck, Sto in enkrat dober tek (prev. iz nem. 1973); Stevo Karapandža, Moji najljubši recepti (prev. iz hrv. 1983); Arne Krüger - Annette Wolter, Kuhajmo z veseljem (prev. iz nem. 1982); Sredozemska kuhinja (prev. iz nem. 2001); Jamie Oliver, Kuhinja do nazga (prev. iz angl. 2002); Sam svoj kuhar (prev. iz angl. 2005); Michele Cranson, Sveže + hitro (prevod iz angl. 2010). 
3.1 Sredozemska jed, imenovana citatno pizza, ki je že po drugi svetovni vojni osvojila svet in postala priljubljena tudi v Sloveniji, je v SSKJ zapisana kot dvojnica s prednostno domačo obliko pica (leta 1979). Dve desetletji kasneje, v SP 2001, zasledimo samo še podomačeno različico pica. Pregled korpusnega gradiva in spletnih kuharskih kotičkov pa kaže, da kljub jasni usmeritvi v SP 2001 tuja in domača različica še vedno tekmujeta med seboj, vendar se ob upoštevanju načela pogostnosti rabe tehtnica nagiba $\mathrm{v}$ korist podomačene različice.

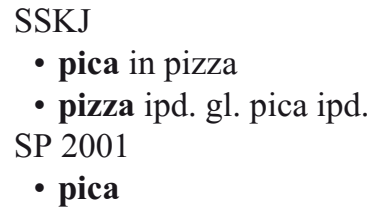

Da je zapis pica le počasi prodiral v rabo, potrjujejo tudi kuharski priročniki, ki so izhajali v obdobju od šestdesetih do devetdesetih let, torej v obdobju izdelave in izida prvih zvezkov SSKJ: če se je ob prvih pojavitvah še omahovalo in so prevajalci skušali najti ustrezen slovenski prevod besedi (pizza alla Napoletanaparadižnikova pita, Gööck 1968: 509), se v rabi hitro začne dosledno zapisovati tuja različica (neapeljska pizza - Karapandža 1983: 170; Sredozemska kuhinja 2001: 34), in šele novejše knjige s področja kulinarike dosledno uveljavljajo podomačeni zapis.

pizza alla Napoletana $(1968) \rightarrow$ neapeljska pizza $(1982,1983) \rightarrow$ pica $(2001,2002)$

Shema 1: Spremljanje sprememb v zapisu - od pizze do pice

Tako dolgotrajno tekmovanje obeh oblik, tuje in podomačene, verjetno izvira tudi iz tega, da je izpeljanka za gostinski lokal kljub nedvoumnemu normativnemu napotilu dolgo nosila (in še nosi) tujo podobo pizzerija in da sta tako pisni kanal kot bližina italijanskega kulturnega prostora močno zavirala prodor podomačenega zapisa. Poleg tega so pizzo v nespremenjeni obliki sprejeli tudi $\mathrm{v}$ angleščino in nemščino, od koder je prek prevodne literature vplivala tudi na slovenščino. V sodobnem slovenskem besedišču na spletnih kulinaričnih forumih še vedno obstajata obe obliki, prednostno se sicer uveljavljajo podomačene različice (pica in picerija), kljub temu pa najdemo zlasti v spletnih in nelektoriranih besedilih nepričakovane zapise tvorjenk (pizzopek), ki nas opozarjajo, da zapis besede ni dokončno ustaljen in da so uporabnikom napotila glede zapisa še vedno dobrodošla.

3.2 Medtem ko smo si prizadevali za zamenjavo nemških izposojenk s slovenskim izrazjem in »izgnali« šnicelj tako iz kuharskih knjig kot tudi iz knjižnega jezika, se je že v prvi slovenski kuharici Magdalene Pleiweis (1902) pojavil an- 
gleški izraz biftek; najdemo ga tudi v vseh obsežnejših kuharicah med obema vojnama in tudi po njej. Da je bil podomačeni zapis uveljavljen in norma enotna, dokazuje tako SP 1962 (biftek) kot večina kasneje izdanih kuharskih knjig. Kljub temu je SSKJ prinesel dvojnični zapis tega izraza, kjer se ob tujem beefsteak pojavi izrecno napotilo na že uveljavljeno domačo različico. Tej usmeritvi sledi tudi SP 2001.

Proces podomačevanja torej ne odstopa od pričakovanj in podoben potek bi pričakovali tudi za besedo steak, ki nastopa kot del zgornje zloženke beefsteak. A ni tako: samostojni steak se pojavi šele v SSKJ, ob njem pa je kot neprednostna dvojnica sprejeta tudi podomačena različica stek (SSKJ):

\section{SSKJ}

- beefsteak gl. biftek

- biftek tudi beefsteak

SP 2001

- beefsteak gl. biftek

- biftek

\section{SSKJ}

- steak in stek

- stek zrezek gl. steak

SP 2001

\section{- steak}

S slovaropisno izbiro tuje različice za prednostno oziroma izhodiščno v slovarskem zapisu je jasno izraženo, da se podomačena različica stek $\mathrm{v}$ gradivu pojavlja le redko, in sicer kot stopnja podomačevanja, za katero ne bi mogli z gotovostjo trditi, da se bo uveljavila; domnevamo pa, da se je pojavila po analogiji z bolj uveljavljenim biftek. Ta težnja se je nato potrdila z izidom SP 2001, ki je ohranil samo tujo različico steak, a žal ni zabeležil novih podomačenih različic, ki so začele prodirati v rabo po izidu SSKJ, in to so oblike, ki sledijo v zapisu angleški izgovarjavi (stejk). Za angleško samoglasniško dvočrkje $e a$ se v slovenščini po pravopisnih priporočilih (SP 2001: § 1100) predvideva bodisi izreka [i] (team > tim) bodisi [e(j)] (steak [ste(j)k]); slednja pojasnjuje tudi omahovanje glede zapisa stek oziroma stejk. In čeprav tuja različica v korpusnem gradivu po pogostnosti še prevladuje, pa novejše kuharske knjige uporabljajo tisto podomačeno različico (Novak - Novak Smej 2009), ki se po izreki približuje angleščini in se tako podomačuje tudi v zapisu (stejk).

\section{steak: stek, stejk}

Shema 2: Spremljanje sprememb v zapisu - od normiranih steak in stek do stejka ${ }^{9}$

9 Odebeljeno so zapisane oblike, ki so že slovarsko normirane. 
Seveda se ob besedi steak ali stejk upravičeno sprašujemo tudi o tem, ali ni to, kot je zapisal že Bajec, odvečna "pritepenka« (1955/56: 235), saj v slovenščini za to predmetnost že obstaja ustrezno poimenovanje zrezek. Ali bo beseda živela ali ne, je zato prepuščeno specialistom za gastronomijo, piscem kuharskih priročnikov in nazadnje tudi uporabnikom splošnega besedja.

Tudi z angleško besedo roast beef, ki v nasprotju s steakom ni kos mesa iz stegna, temveč z govejega hrbta, smo se v slovenščini srečali že v prvi slovenski kuharici M. Pleiweis (1902: 52), in sicer v obliki ros bif, v kuharicah iz obdobja med obema vojnama (Spretna kuharica 1923; Moravec 1927) pa je zapisana kot rosbif.

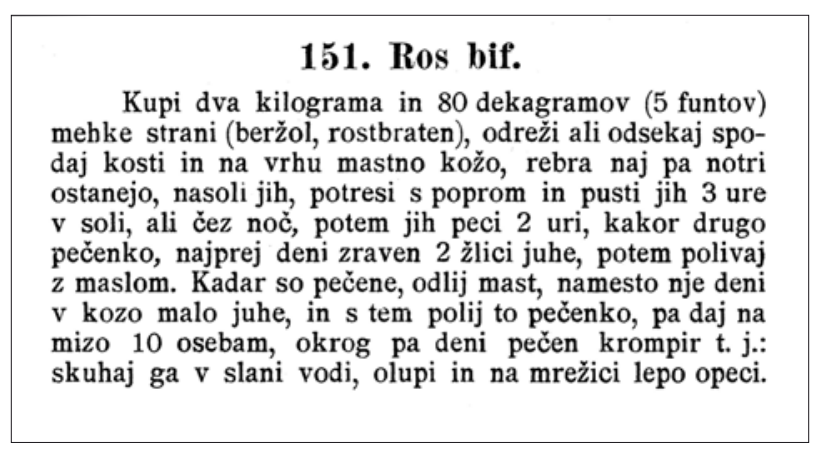

Slika 1: Recept za rosbif iz Slovenske kuharice (Pleiweis 1923: 52)

V priročnikih, izdanih po letu 1945 , najdemo besedo zapisano dosledno v podomačeni različici, pogosteje kot rostbif (KZV 1982: 155; Ivačič 1956: 56; Grum - Levstek 1986: 199; Novak - Novak Smej 2009: 193). Danes je zapis razmeroma ustaljen (rostbif) in tudi normativni priročniki nedvoumno usmerjajo k podomačeni različici zapisa, kljub temu pa nas gradivo prepričuje, da je raba še vedno nedosledna. Med podomačenim zapisom rostbif in tujo obliko, ki je sicer dosledno pisana skupaj roastbeef (SSKJ in SP imata obliko roast beef), je v korpusih, kuharskih forumih in na spletu zaslediti še celo vrsto vmesnih oblik in stopenj, ki potrjujejo, da proces podomačevanja besed, pri katerih gre za zamenjavo več samoglasnikov hkrati, za jezikovne uporabnike vse prej kot preprost.

\section{roast beef: rostbeef, rosbif, roastbif, rostbif, rozbif}

Shema 3: Spremljanje sprememb v zapisu - od angleškega roast beef do domačega rozbif

Za t. i. vmesne stopnje je značilno, da je podomačevanje izpeljano nedosledno. Tako imamo v gradivu oblike zapisa rostbeef, $\mathrm{v}$ katerem je podomačen le prvi del besede $(o a \rightarrow o$ ) in roastbif (v katerem je podomačen le drugi del besede $(e e \rightarrow i)$ ). V gradivu pa odkrijemo tudi podomačene stopnje, ki gredo še korak bliže k popolni prilagoditvi slovenskemu izgovoru oziroma še dlje od zamenjav, navedenih v aktualnih pravopisnih načelih (roztbif in rozbif). Na vprašanje, ali se bo oblikoglasna 
prilagoditev v različici rozbif med uporabniki obdržala, bo odgovoril čas, za ugotavljanje tendence jezikovnih sprememb pa je bistvenega pomena evidentiranje novih pisnih različic v novejšem gradivu.

Tudi prilagajanje angleških besed, v katerih je treba zamenjati več soglasnikov hkrati, je za slovenske uporabnike težavno. Tako je npr. beseda viski, ki je zapisana v podomačeni različici v iztočnici geselskega članka v SSKJ, v SP 2001 pa samo še v podomačeni različici, v korpusnih in spletnih besedilih dobila cel spekter različic, saj zahteva od uporabnika tri zamenjave:

$$
w \rightarrow v \quad h \rightarrow \emptyset \quad(e) y \rightarrow i
$$

Izraz je problematičen tudi zato, ker v angleščini obstajata dve mogoči različici zapisa, tj. whisky in whiskey, oba obravnavana slovenska normativna priročnika pa $\mathrm{v}$ proces podomačevanja vključujeta le prvo, zato bomo v nadaljnji razlagi izhajali iz te.

\section{SSKJ \\ - whisky gl. viski \\ - viski tudi whisky \\ SP 2001 \\ - viski}

Da kljub razširjenosti angleškega jezika za uporabnike podomačevanje ni preprosto in da poznavanje jezika ne pripomore $\mathrm{k}$ hitrejši ustalitvi podomačene oblike, pričajo naslednje $\mathrm{v}$ gradivu potrjene ${ }^{10}$ različice:

- whiski: zapis, v katerem je podomačen le en soglasnik $(y \rightarrow i)$;

- wiski: zapis, v katerem sta podomačena soglasnik in samoglasnik $(h \rightarrow \emptyset$ in $y \rightarrow i)$

- visky: zapis, v katerem sta podomačena dva soglasnika $(w \rightarrow v$ in $h \rightarrow \emptyset)$.

whisky, whiskey: whiski, visky, viski

Shema 4: Spremljanje sprememb v zapisu - različice angleškega whisky/whiskey v slovenščini

Vse se še bolj zaplete, kadar podomačujemo besede, v katerih potekajo tako soglasniške kot samoglasniške zamenjave, pri katerih so po pravopisnih načelih možni različni glasovni ustrezniki. To odlično ponazarja primer angleške besede cocktail, ki je v SSKJ zapisana v treh različicah:

${ }^{10}$ Viri: Priporočljivo je nesti s seboj: whiski, oglje, linex, kakšen prepečenec. (http://blog. unikati.eu) - Jemljem zdravila za astmo in me zanima, ali mi alkohol škoduje pri astmi, saj na žalost skoraj vsako jutro rada spijem kozarček wiskija? (www.24ur.com) - Vprašal me je kaj sem pila, pa sem rekla da sem spila en visky (čeprav sem dve visky kole, pivo in en liker, res pa je da sem tudi jedla). (http://med.over.net/) 


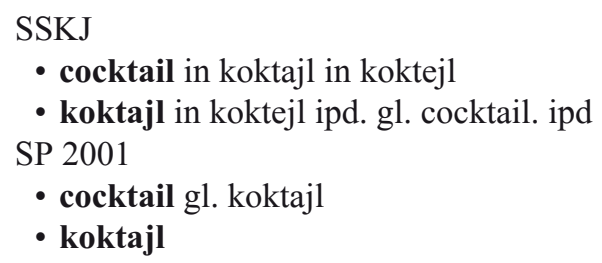

Glede na slovarsko ponujeno možnost treh zapisov seveda ne čudi, da se v kuharskih priročnikih in spletnih besedilih od osemdesetih let naprej pojavljajo vse tri oblike, ki so - upoštevajoč pravila slovenskega SP 2001 pri domačenju besed, prevzetih iz angleščine ( $(1100)$ - vse tudi sprejemljive: angleško dvočrkje $a i$ v slovenščini glasovno (in posledično tudi pisno) domačimo na tri načine: kot aj (cocktail $>$ koktajl), e (fair > fer) in ej (cocktail > koktejl). Ne glede na pravila in rabo je bil v slovarskem delu SP 2001 dvojnični zapis ukinjen, kot prednostna pa določena le različica koktajl.

Kljub kodifikacijski ukinitvi dvojnice se $\mathrm{v}$ rabi vse od pojava te besede $\mathrm{v}$ slovenščini pojavlja veliko število nedosledno izpeljanih podomačevanj, pri katerih se podomači le del besede, drugi deli pa ne:

- coctail, verjetno neustrezno prepisana oblika, pri kateri je tuj soglasniški sklop poenostavljen $(c k \rightarrow c)$;

- koktail, oblika, pri kateri sta soglasnika podomačena $(c \rightarrow k)$, samoglasniški sklop pa ne;

- cocktajl, oblika, pri kateri je podomačen samoglasniški sklop $(a i \rightarrow a j)$, soglasnika $c$ pa sta zapisana nepodomačeno;

- cocktejl, oblika, pri kateri je podomačen samoglasniški sklop $(a i \rightarrow e j)$, soglasnika $c$ pa sta zapisana citatno.

cocktail: coctail, koktail, cocktajl, cocktejl, koktajl, koktejl

Shema 5: Spremljanje sprememb v zapisu - različice zapisa angleškega cocktail v slovenskih besedilih

3.3 Ob besedah rostbif, viski in koktajl, smo lahko opazovali, kako podomačevanje pri besedah, ki prihajajo iz angleščine, ni nič hitrejše ali bolj enosmerno, ampak pogosto zaradi uporabnikovega poznavanja zakonitosti izgovarjave $\mathrm{v}$ izvirnem jeziku še bolj nedosledno izpeljano. Dejavnik, ki ima na proces podomačevanja velik vpliv, je tudi pot, po kateri tuja beseda prodira $v$ jezik. Izrazje za hrano in pijačo, ki je hitro prodrlo v slovenski prostor in našlo svoje mesto na jedilnikih različnih restavracij, gostil in barov, kaže na močno prevladovanje tujega zapisa (npr. juice, espresso, curry) ne glede na usmeritev v SSKJ, ki za juice predlaga podomačeno različico džus, za espresso in curry pa še ne navaja podomačenih različic. 


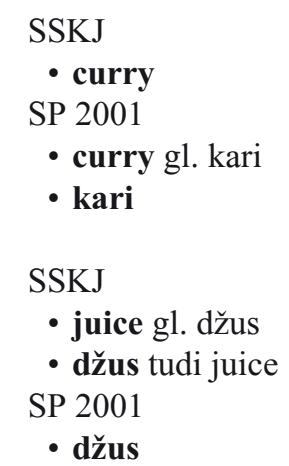

Te uvede šele SP 2001 (ekspreso in kari), zato ne preseneča, da v gradivu pri teh besedah pogostnost tuje oblike (curry) močno prevladuje in da je uveljavljena tudi v najbolj »svežih« prevedenih kuharskih priročnikih (Oliver 2002: 122; Cranston 2010: 149), medtem ko domači avtorji knjižnih in periodičnih publikacij v zadnjem času že uporabljajo povsem podomačene zapise $d \check{u} u$ s in kari (Novak - Novak Smej 2009: 99, 211; Novak - Lenarčič 2009: 162, 395; Odprta kuhinja). V korpusnem gradivu in spletnih kuharskih kotičkih/forumih pa je še posebej pri izrazu za ekspresno kavo veliko različic zapisa, od tuje do domače preko vmesnih bolj ali manj podomačenih stopenj:

\section{espresso: espreso, ekspresso, ekspres, ekspreso}

Shema 6: Spremljanje sprememb v zapisu - od italijanskega espressa do slovenskega ekspresa

Seveda pa k toliko različicam pripomore tudi dejstvo, da italijanski izraz espresso v pomenu 'hitro pripravljena kava' oziroma po SSKJ 'ekspresna kava' uporabnika po analogiji spodbudi k zapisu ekspres in sklepanju: tako kot sta ekspresna vlak in pošta, je lahko ekspresna tudi kava. ${ }^{11}$

3.4 Vendar tudi zapis podomačene različice v priročnikih še ni zagotovilo, da bodo uporabniki usvojili pričakovani zapis besede. Čeprav je pri posameznih besedah lahko iz zapisa že na prvi pogled razvidno, da so tujega izvora, je treba za ustrezno slovenjenje poznati tudi zakonitosti jezika, iz katerega prevzemamo. Jeziki se razlikujejo v na videz povsem vzporednih zakonitostih: na primer pri izgovoru soglasnikov, zapisanih z dvočrkjem ch (angl. ketchup, chutney > slov. kečap, čatni; it. chianti > slov. kjanti; angl. cherry > slov. šeri) ali pri izgovoru podvojenih soglasnikov (angl. pudding > slov. puding; fr. frappé $>$ slov. frape). Ta pojav lahko

${ }^{11}$ Tudi v Šlenčevem italijansko-slovenskem slovarju (1997) je ekspreso slovenski ustreznik italijanskemu espresso. 
- opazujemo pri španskih besedah tortilla in paella, ki ju sicer ustrezno podoma[. č čujemo kot tortilja in paelja, $\mathrm{v}$ korpusu in spletnih virih ter kuharskih knjigah pa N kljub prevladi podomačene različice poleg tujega zapisa še vedno dovolj pogosto zasledimo tudi tortila in paela. Jezikovni uporabniki se morajo pač privaditi, da ima soglasniški sklop $l l \mathrm{v}$ angleških besedah glasovno ustreznico $l$ (angl. grill $>$ slov. gril), v španskih besedah pa $l j$.

\section{SSKJ \\ - tortilja \\ SP 2001 \\ - tortilja}

Medtem ko tortiljo zasledimo že $\mathrm{v}$ obeh normativnih priročnikih, pa uporabnika ne usmerjata od tuje $\mathrm{k}$ domači različici, temveč normirata le podomačeno različico in tako pri uporabniku ne uzavestita, da gre za proces podomačevanja. Morda je tudi zato pri paelji, ki jo uvrščamo k t. i. novejši leksiki, normativno še ne obravnavani, več omahovanja, saj zasledimo različne variante zapisa.

\section{paella: paela, paelija, paelja}

Shema 7: Spremljanje sprememb v zapisu - od španske paelle do slovenske paelje

Še nepodomačeno različico zapisa prinaša tudi najnovejša Kuharska enciklopedija (Novak - Lenarčič 2009: 741), ki tudi sicer izhaja iz izvirnih, tujih poimenovanj, kakor navaja urednik v končnih pojasnilih (Lenarčič 2009: 1283). Ob pregledu novejše leksike za hrano in pijačo $\mathrm{v}$ gradivu ugotovimo, da je mogoče iz palete zapisovalnih različic že izluščiti tisto, ki se je v slovenščini že ustalila, čeprav v standardnih jezikoslovnih priročnikih še ni bila zajeta. Natančnejši pregled gradiva namreč kaže, da podomačevanje novih izrazov poteka podobno kot pri že normiranih prevzetih besedah. Vse novejše besede so $v$ gradivu zabeležene s tujo in domačo različico ter vmesnimi bolj ali manj podomačenimi oblikami, le da so nekatere že bolj ustaljene in pri njih prevladuje podomačena različica: podobno kot pri paelji tudi pri gaspaču najdemo v gradivu več različic zapisa; vmesne stopnje izkazujejo delno podomačevanje, zadnja pa kaže dosledno izpeljavo pravopisnih določil: španska črka $z$ preide $\mathrm{v} s$ in dvočrkje $c h \mathrm{v} \check{c}$.

gazpacho: gaspacho, gazpačo, gaspačo

Shema 8: Spremljanje sprememb v zapisu - gaspačo

3.5 Tudi italijanske besede ciabatta, mocarela, limončelo in druge so v korpusu že zastopane z vmesnimi stopnjami in tudi že ustaljeno podomačeno obliko: 
ciabatta: ciabata, čabata

limoncello: limoncelo, limončelo

moccarella: mozzarela, mozzarella, mocarela

Shema 9: Spremljanje sprememb v zapisu - čabata, limončelo in mocarela

Čeprav se pri teh besedah v novejših kuharskih knjigah uporablja tako tuj kot podomačen zapis, pa korpusi kažejo razvoj oblik, ki smo jih odkrivali tudi pri že normiranem besedju. Torej v jeziku soobstajajo ob tuji različici (ciabatta, mozzarella, limoncello) neustaljene vmesne stopnje (ciabata, mozzarela, mocarella, limoncelo) in dosledno podomačene različice (čabata, mocarela in limončelo), ki dosledno uresničujejo pravopisna priporočila, kako tujim soglasnikom poiščemo slovenski glasovni ustreznik.

3.6 Tudi bežen pogled na novejše izrazje, ki smo ga prevzeli iz angleščine ali nemščine, kaže podoben vzorec soobstajanja različnih oblik. Za ponazoritev smo izbrali besede mafin, kornfleks in musli.

\section{muffin: mufin, maffin, mafin \\ cornflakes: kornflakes, cornfleks, kornfleks}

müsli: muesli, musli

Shema 10: Spremljanje sprememb v zapisu - mafin, kornfleks, musli

3.7 Analiza izbranega besedja, prevzetega v različnih časovnih obdobjih iz različnih jezikov, je pokazala, da kljub težnji po podomačitvi ta proces poteka postopoma, njegova intenzivnost pa je odvisna od prepleta jezikovnih, družbenih in psihičnih dejavnikov. Prav ti pogosto odločilno vplivajo na posameznikov odnos do podomačevanja, a so prikriti, zato jih neupravičeno odrivamo na rob jezikoslovnega interesa. Idealizirana jezikovna podoba, utemeljena z jezikovnimi dejstvi, žal nima tako močnega vpliva na uporabnikovo predstavo o izrazni podobi besede kot napis na škatli, ki jo videvamo na prodajnih policah, ali zapis v jedilnem listu restavracije ali na velikem obcestnem panoju.
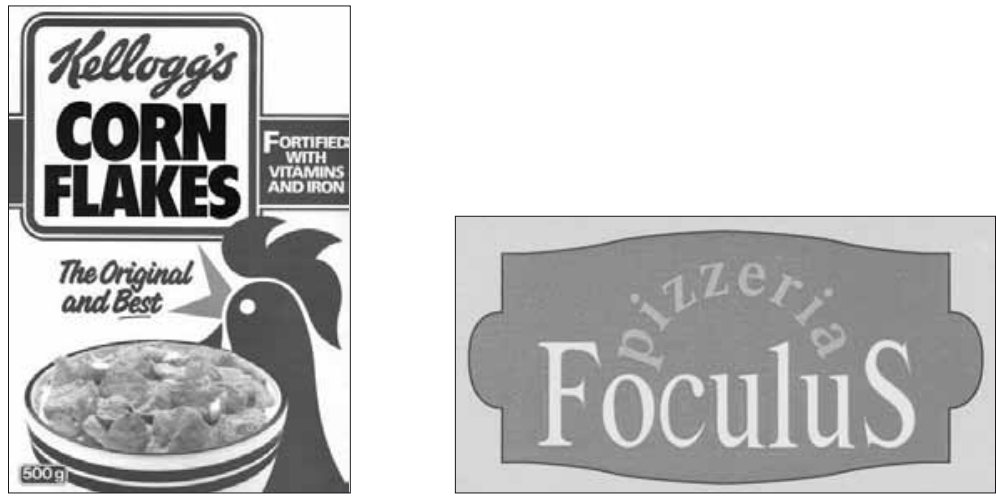

Slika 2: Napis na prodajnem izdelku in na gostinskem lokalu v Ljubljani 
3.8 Ob pregledu gradiva smo odkrili dvoje: (1) večje število t. i. vmesnih različic, pri katerih je proces podomačevanja izpeljan le delno, kar opozarja, da podomačevanje za uporabnike ni preprosto (zlasti takrat, kadar ne poznajo zakonitosti pri razmerju glas - črka v izvornem jeziku oziroma v jeziku, iz katerega prevzemamo); in (2) pojav, ko nove zapisovalne različice »segajo korak dlje« v procesu podomačevanja, kot je predvideno $\mathrm{v}$ aktualnih normativnih priročnikih, in čeprav po pogostnosti še ne prevladujejo, lahko pričakujemo njihovo postopno uveljavljanje (koktejl, stejk, rozbif) tudi v standardnem jeziku. Če nas prvo dejstvo prepričuje, da so normativne ali vsaj informativne jezikoslovne usmeritve pri prevzemanju zaželene in potrebne za poenotenje pisne norme, pa je ob drugem pojavu treba obnoviti že večkrat tematizirano stališče sinhronega jezikoslovja, da enkrat zajeta norma ni dokončna (Toporišič 1992: 294) in da je treba v skladu s tem spoznanjem posodabljati in aktualizirati tudi obstoječe jezikovne priročnike oziroma slovarje.

\section{$4 \quad$ Proces prevzemanja v slovarjih sinhronega jezika}

4.1 V slovarskih prikazih, uveljavljenih do zdaj, so se - upoštevajoč naravo slovarja - pri vprašanju zapisovanja pisnih dvojnic, ki se pojavljajo v procesu prevzemanja, odločali za dva načina obravnave domačih in prevzetih različic:

(1) Ob izdelavi SSKJ so upoštevali referenčno gradivo in se o zaporedju posameznih različic odločali na osnovi gradiva, saj je bilo prvo vodilo informiranje. To je pogosto povzročilo, da so bile na prvem mestu zapisane tuje pisne različice, česar uporabniki niso razumeli kot odsev stanja $\mathrm{v}$ gradivu, temveč kot zgled priporočljivejše jezikovne rabe. Ta način je bil konceptualno bližje sodobnim korpusnim pristopom, vendar je bil zasnovan na precej manjšem gradivskem vzorcu. Tako slovarski prikaz pogosto ne nakazuje težnje $\mathrm{k}$ podomačitvi, čeprav jo raba $\mathrm{v}$ daljšem časovnem intervalu dokazuje.

(2) Ob izdelavi SP 2001, slovarja s poudarjeno normativno funkcijo, je slovarski prikaz podrejen jezikoslovni odločitvi: večina izrazov v slovarju je podomačena, in sicer ne glede na to, ali je $v$ gradivu tak zapis potrjen ali ne. Kljub temu da ta način omogoča, da je uporabnik seznanjen z možnostjo podomačitve, četudi domača različica $v$ rabi še ne prevladuje, pa ne moremo spregledati, da tako zgrajen slovar krši slovaropisno načelo avtentičnosti jezikovnega gradiva. Druga pomanjkljivost tega načina je, da je izvirni zapis besede pogosto izpuščen, zato uporabnik ne uzavesti, da gre za proces podomačevanja, $v$ katerega vstopi tuja različica in izstopi domača.

4.2 Na vprašanje, kako združiti v enem slovarju dobre plati obeh že znanih načinov in tako učinkovito zadovoljiti pričakovanja jezikovnih uporabnikov, je mogoče odgovoriti le, če ugotovimo, kateri podatek jezikovni uporabnik v slovarju dejansko išče. ${ }^{12}$ Čeprav danes slovarji igrajo stransko vlogo v procesu usvajanja jezika (Béjoint 2000:

${ }^{12} \mathrm{Na}$ Slovenskem nimamo nobene raziskave, iz katere bi bilo razvidno, kako si uporabniki jezikovnih priročnikov razlagajo zapis iztočnične besede, dvojničnih zapisov, ali preberejo uvod v slovar in kje pričakujejo več predpisnosti in kje več opisnosti. 
166), pri standardizaciji jezika predstavljajo pomembno sredstvo in mnogi jezikovni uporabniki želijo v slovarjih prav podatek o standardni izrazni podobi besede.

Oba zgoraj opisana pristopa namreč stopata v kontrastivno razmerje, ki ga ponazarja razlika med opisnostjo in predpisovalnostjo slovarja oziroma jezikovnega priročnika: »Popolne opisnosti ni mogoče doseči, saj se slovaropisec ne more izogniti izbiri med posameznimi jezikovnimi različicami, popolna predpisnost pa ni uresničljiva, če je oddaljena od dejanske jezikovne rabe« (Béjoint 2000: 101).

Ob iskanju kompromisnega koncepta $\mathrm{v}$ prihodnjih slovarskih delih s področja sinhronega jezikoslovja bi bilo treba v slovarju upoštevati, da je prevzemanje dolgotrajen proces, kar pomeni, da morata biti v slovarju nakazani obe obliki zapisa, tuja in domača.

Če želimo upoštevati potrebe uporabnikov, se verjetno ne bomo mogli izogniti odločitvi, da ima iztočnični zapis normativno veljavo, da je torej na prvem mestu pogostnostno močnejša rešitev, čemur pa lahko zadostimo le, če spremljamo gradivo v dovolj velikem obsegu, kar bi nam omogočal zvrstno uravnotežen gradivski korpus.

Tudi slovarski prikaz dvojne izrazne podobe je lahko dvojničen na makrostrukturni ali mikrostrukturni ravni:

- MiKROSTRUKTURNA RAVEN

Dvojnični zapisi so obravnavani v okviru istega slovarskega sestavka, na prvem mestu je pogostejša različica:

steak tudi stejk

ciabata tudi čabata

rostbif in roastbeef

Slaba stran tega prikaza je, da so pri večji pogostnosti tujega zapisa tudi med slovarskimi zgledi navedeni le tuji zapisi (na primer krompir iz pečice s curryjem in rožmarinom), o rabi podomačene različice pa uporabnik ni obveščen. Pri zgledih, v katerih gradivo izkazuje uveljavljenost domačega zapisa (džus, koktajl), pa v slovarju težko najdemo izvorno besedo (juice, cocktail). Posledično je bolj zapleten tudi slovarski sestavek, saj je treba načeloma enakovrednima iztočničnima oblikama dopisati vse pravorečne in slovnične podatke:

steak -a tudi stejk -a m [prva oblika stejk]

- MAKROSTRUKTURNA RAVEN

Dvojnični zapisi so obravnavani v ločenih slovarskih sestavkih:

pizza gl. pica

pica -e ž $\mid<$ it. pizza|

mousse -- $\check{z}$

Pomanjkljivost tega načina je, da rešitev pri tistih posameznih besedah v jeziku, ki pogosto ohranijo citatni zapis (cordon bleu, mousse, al dente), ne predvideva domače različice. Zato je treba take primere obravnavati posamično, ločevanje med prvimi in drugimi pa določiti na podlagi korpusnega gradiva. 
Dobra stran tega prikaza je, da je informacija za uporabnika bolj nedvoumna, razmerje med različicami je določeno bolj eksplicitno, povečana je usmerjevalnost in praktična obvestilnost.

4.3 Pomembno dejstvo, ki ga je treba ob slovarskem normiranju upoštevati, je proces determinologizacije, s katerim v vsakdanjo govorico sprejmemo veliko količino novega besedja iz strokovnega jezika, normiranje le-tega pa ni oprto na normativne usmeritve posameznih strok. Terminološko izrazje je namreč v okviru stroke normirano po drugačnih načelih in teži k enopomenskosti. Zato bi bilo ob normiranju ustreznega zapisa nujno povezati rezultate splošnih, tj. referenčnih in terminoloških korpusov.

4.4 Kljub vsem možnostim, ki jih ponujajo jezikovne tehnologije in informacijska orodja, ko zasledujemo jezikovno rabo, pa se je vendarle treba zavedati, da za izrecno vrednotenje in razvrščanje dvojničnih zapisov nimamo zajetega gradiva v vsej jezikovni raznolikosti - dvojnica namreč ne sme biti posledica pomanjkanja gradiva ali omahovanja jezikoslovca, temveč odraz dejanskega stanja v normi. Doba elektronskih slovarjev, v kateri se lakoničnost slovarskega metajezika umika želji po primerni obvestilnosti slovarja, leksikografom ponuja še neodkrite in nepreizkušene načine slovarskega prikaza dejstev, opisanih v prispevku. Zato je treba slovarske sestavke z mislijo na uporabnikove zadrege in z upoštevanjem povečanih možnosti slovarskega prikaza preoblikovati tako, da bodo uporabnika dobro informirali o razvojnih tendencah jezika, o tem, kateri pojavi v rabi jezika so $\mathrm{s}$ kolektivno navado postali nadindividualni, torej del splošno sprejete norme standardnega jezika, in v kakšnem razmerju so do jezikovnega sistema, pri čemer upoštevamo tezo, da je oblika, ki se prilega jezikovnemu sistemu, boljša od tiste, ki ga krši (Molde 1979, nav. po Orešnik 1995: 116).

\section{Viri}

Cranston 2010 = Michele Cranston, Sveže + hitro, Olševek: Narava, 2010.

eSP 2003 = Slovenski pravopis, elektronska izdaja na CD-ROM-u, Ljubljana: ZRC SAZU - Založba ZRC.

Gööck 1968 = Roland Gööck, Nova velika kuharska knjiga, Ljubljana: Mladinska knjiga, 1968.

Gööck 1973 = Roland Gööck, Sto in enkrat dober tek, Ljubljana: Mladinska knjiga, 1973.

Grum 1956 = Andreja Grum (ur.), Velika sodobna kuharica, Ljubljana: Naša žena, 1956.

Grum - Levstek 1986 = Andreja Grum - Pepika Levstek, Kuharstvo, Ljubljana: DZS, 1983.

Ilc 1994 = Marija Ilc, Kuharica sestre Vendeline: slovenska meščanska kuhinja, Ljubljana: Vale-Novak, 1994. 
Ivačič 1965 = Ivan Ivačič, Kuharska knjiga, Celje: Mohorjeva družba, 1965.

Karapandža 1983 = Stevo Karapandža, Moji najljubši recepti, Zagreb: Znanje, 1983.

Krüger - Wolter 1982 = Arne Krüger - Annette Wolter, Kuhajmo z veseljem, Ljubljana: Založba Centralnega zavoda za napredek gospodinjstva, 1982.

Moravec 1927 = Marija Moravec, Iz francoske meščanske kuhinje: nad 1000 kuharskih receptov in pripombe o serviranju, Ljubljana: Belo-modra knjižnica, 1927.

Novak - Novak Smej 2009 = Luka Novak - Valentina Novak Smej, Ljubezen skozi želodec, Ljubljana: Vale-Novak, 2009.

Novak - Lenarčič 2009 = Bogdan Novak - Simon Lenarčič, Kuharska enciklopedija, Ljubljana: Modrijan, 2009.

Oliver 2002 = Jamie Oliver, Kuhinja do nazga, Ljubljana: Vale-Novak, 2002.

Pleiweis 1902 = Magdalena Pleiweis, Slovenska kuharica ali Navod okusno kuhati navadna in imenitna jedila, ponatis izd. iz leta 1902, Ljubljana: DZS, 2004.

Pucelj 1938 = Riko Pucelj, 110 novih kuharskih receptov, Celje: Družba sv. Mohorja, 1938.

Sam svoj kuhar 2005 = Sam svoj kuhar: po korakih, Ljubljana: Prešernova družba, 2005.

SP 1962 = Slovenski pravopis, Ljubljana: SAZU - DZS, 1962.

SP 2001 = Slovenski pravopis, Ljubljana: SAZU - ZRC SAZU - Založba ZRC, 2001.

Spretna kuharica 1923 = Spretna kuharica: nova velika kuharska knjiga: navodilo, kako se kuhajo dobra in okusna jedila, Ljubljana: A. Turk, 1923.

Sredozemska kuhinja 2001 = Sredozemska kuhinja, Tržič: Učila, 2001.

SSKJ = Slovar slovenskega knjižnega jezika 1-5, Ljubljana: SAZU oz. ZRC SAZU (izd.) - DZS (zal.), 1970-1991.

Šlenc 1997 = Sergij Šlenc, Veliki italijansko-slovenski slovar $=$ Il grande dizionario italiano-sloveno, Ljubljana: DZS, 1997.

\section{Spletni viri}

FidaPLUS = Korpus slovenskega jezika FidaPLUS (http://www.fidaplus.net, vpogled april 2010).

Gurman = Spletni portal Gurman, društvo dobrih okusov (www.gurman.eu, vpogled april 2010).

Kulinarična Slovenija $=$ Spletni portal Kulinarična Slovenija, največji slovenski kulinarični portal (www.kulinarika.net, vpogled april 2010).

Nova beseda $=$ Besedilni korpus Nova beseda (http://bos.zrc-sazu.si, vpogled april 2010). 


\section{$-\quad$ Navedenke}

Aitchison 1991 = Jean Aitchison, Language change: progress or decay?, Cambridge: Cambridge University Press, 1991.

Bajec 1955/56 = Anton Bajec, Sprehodi po slovenskem besedišču, Jezik in slovstvo $1(1955 / 56)$, št. 6-7, 235-237.

Béjoint $2000=$ Henri Béjoint, Modern lexicography: an introduction, Oxford: Oxford University Press, 2000.

Bezlaj 1982 = Franc Bezlaj, Etimološki slovar slovenskega jezika 2: K-O, Ljubljana: SAZU (izd.) - Mladinska knjiga (zal.), 1982.

Bogataj 2008 = Janez Bogataj, Slovenija je kulinarično dežela različnosti, Večer (24. 4. 2008), 41.

Lenarčič 2009 = Simon Lenarčič, Pojasnila o jezikovnih in pravopisnih rešitvah v Kuharski enciklopediji, v: Kuharska enciklopedija, Ljubljana: Modrijan, 2009, 1283-1289.

Orešnik 1995 = Janez Orešnik, Uradi za jezik v Skandinaviji, Ljubljana: SAZU, 1995.

Pogačnik 2003 = Aleš Pogačnik, Prevzemanje besed v slovenščini, Jezik in slovstvo 48 (2003), št. 6, 25-48.

Snoj 2005 = Marko Snoj, O prevzetih besedah, tujkah in izposojenkah, Slovenski jezik 2005, št. 5, 113-122.

Thomason 2001 = Sarah G. Thomason, Language contact, Edinburg: Edinburg University Press, 2001.

Thomason - Kaufman 1988 = Sarah Grey Thomason - Terrence Kaufman, Language Contact, Creolization, and Genetic Linguistics, Berkeley - Los Angeles: University of California Press, 1988.

Toporišič 1971 = Jože Toporišič, Pravopis, pravorečje in oblikoslovje v Slovarju slovenskega knjižnega jezika I, Slavistična revija 19 (1971), št. 3, 285-318.

Toporišič 1972 = Jože Toporišič, Prevzete prvine slovenskega knjižnega jezika (glasovi, pisava, oblike, tvorba, besede), Slavistična revija 20 (1972), št. 3, $55-75,222-229$.

Toporišič 1992 = Jože Toporišič, Enciklopedija slovenskega jezika, Ljubljana: Cankarjeva založba, 1992. 


\section{The nativization process and how recently borrowed words are written}

\section{Summary}

This article examines how words recently borrowed into Slovenian from Germanic and Romance languages are written. It presents borrowing as a linguistic process of change in which it is impossible to predict which nativized forms will become established sooner, or which foreign forms will never be nativized, because this not only depends on internal linguistic rules but is also influenced by social and psychological factors.

This study is based on an analysis of material from the semantic field of food and drink. The universality as well as the everyday and vital importance of food offers the opportunity to observe and compare the use of borrowed lexemes in various functional forms of the language and over a long period of time, making it possible to compare the borrowing process today and in the past not only in terms of degree of nativization, but also social (i.e., nonlinguistic) influences.

We observed how users nativize borrowed words from the semantic field of food in text corpuses, online texts specific to cooking, the weekly Odprta kuhinja (Open Kitchen) supplements to the newspaper Delo, and in the two current normative dictionaries: Slovar slovenskega knjižnega jezika (Standard Slovenian Dictionary, 1970-1991) and Slovenski pravopis (Slovenian Normative Guide, 2001). To create terminological balance in the study, a number of copyrighted cookbooks were selected from different periods in the second half of the twentieth century and the beginning of the twenty-first century.

The analysis examines the written forms pizza - pica, beefsteak - biftek, steak - stek, roast beef - rostbif, whisky and whiskey - viski, cocktail - koktajl, koktejl, juice - džus, espresso - ekspreso, curry - kari, tortilla - tortilja, paella - paelja, gazpacho - gaspačo, ciabatta - čabata, mozzarella - mocarela, limoncello - limončelo, muffin - mafin, cornflakes - kornfleks, and müsli - musli. It showed that, despite the tendency to nativize, this process takes place gradually and its degree depends on the intermingling of linguistic, social, and psychological factors. Psychological factors in particular often have a decisive influence on nativization, but these are hidden and so are unjustifiably relegated to the margin of linguistic interest. The examination of the material identified a large number of "intermediate" variants in which the nativization process had only partially been carried out, drawing attention to how demanding this process is for language users. Alongside standardized variants, new spelling variants have appeared that "go a step further" in the nativization process than is anticipated in the current normative guides.

The article continues by critically presenting the borrowing process in synchronic Slovenian dictionaries in use to date and today, in which there is a contrast between the descriptive and prescriptive function of a dictionary or linguistic guide, and by presenting proposals for overcoming this opposition in the future. Here it is shown that the dictionary presentation of double forms of terms may be doubled at the macrostructure level (e.g., ciabata also čabata, rostbif and roastbeef) or micro- 
- $\quad$ structure level (e.g., pizza see pica, pica - ef. $\mid<$ Ital. pizza $)$. It is therefore necessary [a] to shape dictionary entries such that users are well informed about the developmenN tal tendencies of the language, which phenomena in language use are part of the - $\quad$ generally accepted standard language norm, and what their relationship is to the 즈 language system. 